\title{
Three Levels of Naturalistic Knowledge
}

\author{
Andreas Stephens
}

\author{
Preprint \\ The final publication is available at Springer via: \\ http://dx.doi.org/10.1007/978-3-030-12800-5
}

\begin{abstract}
A recent naturalistic epistemological account suggests that there are three nested basic forms of knowledge: procedural knowledge-how, conceptual knowledge-what, and propositional knowledge-that. These three knowledgeforms are grounded in cognitive neuroscience and are mapped to procedural, semantic, and episodic long-term memory respectively. This article investigates and integrates the neuroscientifically grounded account with knowledge-accounts from cognitive ethology and cognitive psychology. It is found that procedural and semantic memory, on a neuroscientific level of analysis, matches an ethological reliabilist account. This formation also matches System 1 from dual process theory on a psychological level, whereas the addition of episodic memory, on the neuroscientific level of analysis, can account for System 2 on the psychological level. It is furthermore argued that semantic memory (conceptual knowledge-what) and the cognitive ability of categorization are linked to each other, and that they can be fruitfully modeled within a conceptual spaces framework.
\end{abstract}




\section{Introduction}

INVESTIGATIONS REGARDING KNOWLEDGE have been going on for millennia while the concept still lacks a sharp and widely accepted definition (see, e.g., Markie 2013; Samet and Zaitchik 2014). However, many philosophers nowadays heed naturalism and consider it the job of science to provide our best explanations. Furthermore, as cognitive sciences have progressed, much relevant information regarding our cognitive faculties and knowledge is indeed available. We understand the world through multiple models, but since different sciences explore cognition and knowledge on different levels of analysis, it is not clear if, or how, the different accounts of knowledge they provide can, or should, be united (see, e.g., Dupré 1993; Mitchell 2003; Horst 2016).

In an attempt to offer some clarity and coherence, Gärdenfors and Stephens (2017) have argued that there are three nested basic forms of knowledge: procedural knowledge-how, conceptual knowledge-what, and propositional knowledge-that. The tri-partite knowledge-account is grounded in cognitive neuroscience where the three forms of knowledge are mapped to procedural, semantic, and episodic memory respectively. While there is an extensive and on-going epistemological discussion concerning the traditional forms knowledge-how and knowledge-that (see, e.g., Ryle 1949; Stanley 2011; Fantl 2016), a lot remains to be explored regarding the form knowledge-what, which Gärdenfors and Stephens argue is generated by inductive reasoning.

Moreover, in encouragement of a multi-disciplinary and multi-level development of our understanding of knowledge, cognition and behavior (see, e.g., Frank and Badre 2015), it can be pointed out that:

"[T]he neurosciences are reshaping the landscape of the behavioral sciences, and the behavioral sciences are of increasing importance to the neurosciences, especially for the rapidly expanding investigations into the highest level functions of the brain." (Berntson and Cacioppo 2009, p. xi)

This article attempts to broaden the proposed knowledge-account and our understanding of knowledge-what by investigating two issues. First, the prospect of integrating the knowledge-account with models from two other scientific perspectives (cognitive ethology and cognitive psychology) on higher levels of analysis will be explored. If successful, such integration would increase the knowledge-account's plausibility. By encompassing three levels of analysis, it would present a naturalistic framework arguably fairly close to a traditional epistemological outlook. Second, the link between the knowledgeform knowledge-what and categorization will be considered. I will loosely follow a prototype theoretical interpretation and view categorizations as natural cognitive phenomena where organisms try to acquire as much information as possible of the surrounding structured world, while minimizing their 
energy-expenditure (see, e.g., Rosch 1975a, 1975b). According to such an interpretation, objects in a category are compared in relation to how representable they are, and the most representable object is seen as a prototype. Other objects can then be compared in relation to how similar they are to the prototype (see, e.g., Gädenfors 2000, p. 84). This inquiry diverges from Gärdenfors and Stephens' discussion, which centers on the specific role of inductive inferences, and can thus be seen as a complementary development of their account.

After this short introduction section 2 will give an outline of Gärdenfors and Stephens' knowledge-account grounded in cognitive neuroscience. Section 3 then investigates knowledge from the perspective of cognitive ethology, and the possibility of integrating the cognitive ethological account with the neuroscientific account. Section 4 continues by inquiring into how a cognitive psychological account can be integrated with both former accounts, and in section 5 it is lastly argued that conceptual knowledge-what and categorizations can be fruitfully modeled within a conceptual spaces framework (Gärdenfors 1990, 2000, 2014).

\section{Cognitive Neuroscience: Knowledge and Memory}

Even though there are various different models and theories pertinent to understand knowledge from a neuroscientific proximate perspective, Gärdenfors and Stephens (2017) single out and use Tulving's (1985; see also 1972) seminal account of memory and consciousness. This is, arguably, a reasonable basis since Tulving's account has been extremely influential and is often used as a starting-point in neuroscientific research even by those who ultimately deviate from it. Knowledge, from a neuroscientific perspective, is thought to have its foundation in long-term memory (LTM), and Tulving divides LTM into three nested parts, illustrated in Figure 1: procedural memory, semantic memory, and episodic memory, where '[...] procedural memory entails semantic memory as a specialized subcategory, and in which semantic memory, in turn, entails episodic memory as a specialized subcategory.' (Tulving 1985, pp. 2-3, italics removed; see also Fletcher et al. 1999; Goel and Dolan 2000; Kan et al. 2009; Barrett 2015; Kim 2016). Tulving argues that:

"Procedural memory [...] is concerned with how things are done - with the acquisition, retention, and utilization of perceptual, cognitive, and motor skills. Semantic memory - also called generic [...] or categorical memory [...] - has to do with the symbolically representable knowledge that organisms possess about the world. 
Episodic memory mediates the remembering of personally experienced events [...]." (Tulving 1985, p. 2)

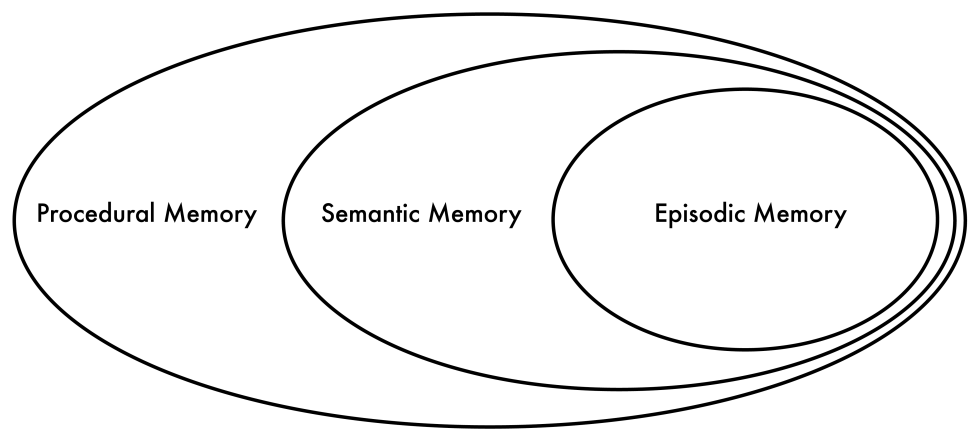

Figure 1 Tulving's nested account of the LTM. Procedural memory entails semantic memory as a specialized subcategory, and semantic memory entails episodic memory as a specialized subcategory.

With this partitioning as an underpinning, and trailing the neuroscientific canon, procedural knowledge-how (the knowledge of how to ride a bike an ability) readily maps to non-declarative procedural memory. This form of memory governs actions while it to a large extent is automatic and nonconscious. Through repetition we can learn, but we do it without being able to put all aspects of this knowledge into words. To use the above-mentioned example, we might be able to describe - in broad terms - what one should think about when learning how to ride a bike. But these instructions will not be enough to master the complicated motoric patterns necessary to execute the ability. This form of knowledge and learning-process instead demands practice. Procedural memory relies on the complex and interconnected performance of perceptual and motor pathways, involving, for example, the basal ganglia, neocortex, cerebellum, striatum, and the premotor- and primary motor cortex (see, e.g., Kandel et al. 2013). Many animals are endowed with procedural memory and are capable of procedural knowledge-how (Tulving 2002).

Semantic memory governs 'an individual's store of knowledge about the world. The content of semantic memory is abstracted from actual experience and is therefore said to be conceptual, that is, generalized and without reference to any specific experience.' (Binder and Desai 2011, p. 527). Semantic memory is crucial for numerous animals navigating a complex world (Roberts 2016). Moreover, an agent's ability to contemplate concepts and their relations, to perform inductive inferences and, as I want to emphasize, to categorize are all linked to semantic memory: 


\begin{abstract}
"Categorization is fundamental to understanding and using the concepts in semantic memory, since this process helps organize our knowledge and relate a test object to other known objects in the world. Categorization also allows us to engage in activities such as understanding unfamiliar objects and learning about novel objects." (Grossman, Smith et al. 2002, p. 1549)
\end{abstract}

Gärdenfors and Stephens (2017) map conceptual knowledge-what (the knowledge of what a category consists in: dogs characteristically have four legs) to semantic memory. Similar formulations are indeed already in use in neuroscientific discussions:

"Thus humans use conceptual knowledge for much more than merely interacting
with objects. All of human culture, including science, literature, social institutions,
religion, and art, is constructed from conceptual knowledge. We do not reason, plan
the future or remember the past without conceptual content - all of these activities
depend on activation of concepts stored in semantic memory." (Binder and Desai
2011, p. 527)

Furthermore, several fMRI studies link the neural correlations of semantic encoding and semantic processing to '[...] many cognitive tasks, from perception, categorization, to explicit reasoning in problem-solving and decisionmaking.' (Goel and Dolan 2000, p. 110). In fact, many findings directly link semantic memory and categorization. Although, some discrepancies in neural activation is to be expected depending on, among other factors, variability regarding which aspects is in focus and regarding how stimulus is presented to test subjects (see, e.g., Grossman, Koenig et al. 2002). For example, Yee et al. (2014) explicitly relate conceptual knowledge to semantic memory and claim that such knowledge is distributed over many brain regions, which makes it flexible and able to handle varying contexts. Semantic memory relies on associative pathways, involving, amongst other areas, the prefrontal cortex, the lateral-, ventral- and medial temporal cortex, basal ganglia, and hippocampus (see, e.g., Kandel et al. 2013):

"Semantic knowledge is stored in distinct association cortices and retrieval depends on the prefrontal cortex. [...] Semantic knowledge is distinguished from episodic knowledge in that it is typically not associated with the context in which the information was acquired. It is stored in a distributed manner in the neocortex, including the lateral and ventral temporal lobes." (Kandel et al. 2013, pp. 1449-1450)

Lastly, propositional knowledge-that (the knowledge that Stockholm is the capital of Sweden) maps to declarative episodic memory, governing factual remembrances and a sense of time - thereby playing a large part in how agents plan for the future: 
"Memory for specific experiences is called episodic memory, although the content of episodic memory depends heavily on retrieval of conceptual knowledge. Remembering, for example, that one had coffee and eggs for breakfast requires retrieval of the concepts of coffee, eggs and breakfast. Episodic memory might be more properly seen as a particular kind of knowledge manipulation that creates spatial-temporal configurations of object and event concepts." (Binder and Desai 2011, p. 527)

Gärdenfors and Stephens (2017), ascribe facts to episodic memory (propositional knowledge-that) rather than to semantic memory (conceptual knowledgewhat) - an interpretation somewhat similar to how for example Renoult et al. (2016) view 'autobiographical facts' as grounded in episodic memory. Episodic memory is crucially involved in self-awareness and first-person phenomenology. Since it according to Tulving's account is an evolutionarily later specialized subcategory, as shown in (Fig. 1), it is largely dependent on semantic memory:

"Episodic memory refers to a complex and multifaceted process which enables the retrieval of richly detailed evocative memories from the past. In contrast, semantic memory is conceptualized as the retrieval of general conceptual knowledge divested of a specific spatiotemporal context. [... T] he available evidence [...] converges to highlight the pivotal role of semantic memory in providing schemas and meaning whether one is engaged in autobiographical retrieval for the past, or indeed, is endeavoring to construct a plausible scenario of an event in the future. It therefore seems plausible to contend that semantic processing may underlie most, if not all, forms of episodic memory, irrespective of temporal condition." (Irish and Piguet 2013, p. 1)

Episodic memory relies on attentional pathways, involving, for example, the prefrontal cortex, and the ventral-fronto- and medial temporal cortex (see, e.g., Kandel et al. 2013).

Episodic memory is conventionally considered uniquely human although there is increasing evidence indicating that animals - primarily rats, corvids, and great apes - have some form of episodic memory. For example PanozBrown et al. (2016, p. 2821; see also Roberts 2016) argue that '[...] rats remember multiple unique events and the contexts in which these events occurred using episodic memory and support the view that rats may be used to model fundamental aspects of human cognition.' Clayton et al. (2001, p. 1483) contend that '[...] jays form integrated memories for the location, content and time of caching. This memory capability fulfills Tulving's behavioural criteria for episodic memory and is thus termed "episodic-like".' Rilling et al. (2007, p. 17149) describe how their '[...] results raise the possibility that the resting state of chimpanzees involves emotionally laden episodic memory retrieval and some level of mental self-projection, albeit in the absence of language and conceptual processing.' As a last example, Allen 
and Fortin (2013, p. 10380) even claim that '[...] core properties of episodic memory are present across mammals, as well as in a number of bird species.'

Tulving (2005) discusses the issue of episodic memory in animals and points out that:

"It depends partly on what one means by episodic memory, partly on the kinds of evidence one considers, and partly on how one interprets the evidence. When episodic memory is defined loosely as 'memory for (specific) past events,' then the standard commonsense answer is that of course animals have it." (Tulving 2005, p. $35)$

However, Tulving highlights the importance of a less anthropomorphic perspective than this 'commonsense' understanding. Focusing on mental time travel, which is an essential aspect of episodic memory in humans and a distinguishing trait, he argues that:

"[...] only human beings possess "autonoetic" episodic memory and the ability to mentally travel into the past and into the future, and that in that sense they are unique." (Tulving 2005, p. 4)

The issue might be impossible to conclusively settle, since there are valid arguments for a variety of interpretations that ultimately hinge on how one choose to interpret the relevant terms, theories and evidence. Nevertheless, even if one accepts that animals other than humans can have episodic memories; it is to a significantly lesser degree. This fits with the view that episodic memory (propositional knowledge) is evolutionarily subsequent to the two other forms of LTM (Tulving 1985, 2002, 2005).

As previously mentioned, a way to increase the plausibility of the abovedescribed knowledge-account is to investigate whether it is possible to integrate with models - from other sciences - on other levels of analysis. Since '[t]he neural basis of behavior cannot be properly characterized without first allowing for independent detailed study of the behavior itself [...]' (Krakauer et al. 2017, p. 488), the next section will explore the possibility of such integration by using Kornblith's (2002) analysis and account of knowledge from cognitive ethology (see also, e.g., Mitchell 2003; Cellucci 2017).

\section{Cognitive Ethology: Evolution and Reliability}

'The biological study of animal behavior, including its phenomenological, causal, ontogenetic, and evolutionary aspects, is a discipline known as ethology' (Anderson and Perona 2014, p. 18). Ethology investigates animal behavior concentrating on natural environmental settings. Moreover, there is 
an ongoing discussion if such behavior is intentional - and if so, to what degree (see, e.g., Allen and Bekoff 1995; Wynne 2007; Shettleworth 2010). From an ultimate perspective, knowledge can be seen as the result of a phylogenetic and genotypic adaptive (functional) process, which shapes the cognitive faculties of agents (see, e.g., Plotkin 1993; Avital and Jablonka 2000):

"What is actually meant is that knowledge is a complex set of relationships between genes and past selection pressures, between genetically guided developmental pathways and the conditions under which development occurs, and between a part of the consequent phenotypic organization and specific features of environmental order." (Plotkin 1993, p. 228)

Our cognitive faculties are the result of evolutionary processes that has formed our sense organs and cognitive architecture. So, our evolutionarily molded cognitive faculties enable, as well as constrain, what we know (Plotkin 1993, p. 162).

In addition to these innate features, agents can acquire knowledge by learning, an ontogenetic aspect '[...] indicating processes by which the individual, thanks to phenotypic modifications, accommodates to novel circumstances in the course of its life.' (Serrelli and Rossi 2009, p. 18). In connection to ethology, implicit learning and implicit memory are central '[... involving] a wide variety of brain regions, most often cortical areas that support the specific perceptual, conceptual, or motor systems recruited to process a stimulus or perform a task.' (Kandel et al. 2013, p. 1459). Implicit learning splits into non-associative and associative learning, where nonassociative learning includes responses to repeatedly encountered stimulus, in the form of habituation, where an agent's response diminishes by repeated exposure to a stimulus, and sensitization, where exposure strengthens a response. Associative learning involves how agents learn to link (associate) different stimuli to each other, in the form of conditioning by stimulus, response, and grasped relationships (see, e.g., Kandel et al. 2013).

Non-associative and associative learning thus match procedural respectively semantic memory, and, even though the focus is on particular brain systems rather than on implicit memory generally, for example Ullman (2016) argues that:

"Procedural memory involves a network of interconnected brain structures rooted in frontal/basal-ganglia circuits, including frontal premotor and related regions, particularly BA 6 and BA 44. [...] This circuitry underlies the implicit (nonconscious) learning and processing of a wide range of perceptual- motor and cognitive skills, tasks, and functions [...] including navigation, sequences, rules, and categories." (Ullman 2016, p. 956) 
Illuminating the cognitive ethological position, Kornblith (2002, see also 1993) offers a fruitful discussion about 'fitness' and how animals that have knowledge about their changing environment better survive and thrive $1^{1}$ In a more traditional epistemological terminology, he points out that cognitive ethology provides:

"[...] a large literature on animal cognition, and [how] workers in this field typically speak of animals knowing a great many things. They see animal knowledge as a legitimate object of study, a phenomenon with a good deal of theoretical integrity to it. Knowledge, as it is portrayed in this literature, does causal and explanatory work." (Kornblith 2002, pp. 28-29)

According to Kornblith's interpretation, cognitive ethology supports a reliabilist account of knowledge where knowledge should be seen as demanding reliably produced true beliefs $(\mathrm{RTB}) \mathrm{:}^{2}$

"[...] I will argue that the kind of knowledge that philosophers have talked about all along just is the kind of knowledge that cognitive ethologists are currently studying. Knowledge explains the possibility of successful behavior in an environment, which in turn explains fitness. [... W] e must appeal to a capacity to recognize features of the environment, and thus the true beliefs that [... someone] acquire will be the product of a stable capacity for the production of true beliefs. The resulting true beliefs are not merely accidentally true; they are produced by a cognitive capacity that is attuned to its environment. In a word, the beliefs are reliably produced. The concept of knowledge which is of interest here thus requires reliably produced true belief." (Kornblith 2002, pp. 29-30, 57-58)

As reliabilism is generally coupled with externalist forms of justification such as truth-connectivity and reliability where an agent does not need to have cognitive access to her beliefs, it fits well with the description of the nonconscious non-associative and associative learning (see, e.g., Kandel et al. 2013; Ullman 2016) $3^{3}$ An integration of the cognitive ethological reliabilist account and the cognitive neuroscientific account is accordingly possible by focusing on the two evolutionarily prior forms of memory and knowledge - procedural memory (procedural knowledge-how) and semantic memory (conceptual knowledge-what).

1 For a critique of Kornblith's position see for example Bermúdez (2006).

2 Kornblith argues that cognitive ethology 'gives us the only viable account of what knowledge is.' (Kornblith 2002, p. 135, my italics). However, he does not motivate this restriction in a convincing way - pointed out by for example Kusch (2005) - and so this aspect of Kornblith's otherwise fruitful ideas will not be heeded here.

3 Episodic memory (propositional knowledge) governing self-awareness and first-person phenomenology, on the other hand, is more naturally linked to internalism and forms of justification such as rationality and cognitive access (Tulving 2005; Alston 2005). 


\section{Cognitive Psychology: Intuition and Deliberation}

Cognitive psychology investigates how human mental processes, including knowledge, are connected to behavior, using both bottom-up and top-down methods.

On a psychological level of analysis, implicit memory, implicit learning, and non-associative learning are all seen as being linked to procedural memory (procedural knowledge). In various forms of behaviorism these concepts have been investigated with a focus on reinforcement and punishment. However, in many theories, explicit memory and explicit learning take a central place, governing rule learning, awareness, and active remembrance of facts, being linked to episodic memory (propositional knowledge) (Kandel et al. 2013):

\footnotetext{
"[Explicit memory] is the deliberate or conscious retrieval of previous experiences as well as conscious recall of factual knowledge about people, places, and things. [...] Explicit memory is highly flexible; multiple pieces of information can be associated under different circumstances." (Kandel et al. 2013, p. 1446)
}

As an in-between, semantic memory (conceptual knowledge) is involved in both implicit and explicit memory, being linked to associative learning, pattern recognition, categorization, and prototype-matching. Regarding conceptual knowledge and categorization, for example Csibra and Gergely (2006) inquire into how teaching, and learning from teaching, should be viewed as a key adaptation for the transfer of knowledge between humans (see also Gärdenfors and Högberg 2017; Gergely et al. 2007). To facilitate social learning and teaching, they highlight how pedagogy offers a possibility to transfer generalizable knowledge, instead of just factual information, from a (active) teacher to a learner. Such generalizable knowledge does not only pertain to a specific situation but can be applied in many different contexts, which is essential for the ability to categorize. Csibra and Gergely (2009) develops their thoughts on generalizable knowledge:

\footnotetext{
"If I point at two aeroplanes and tell you that 'aeroplanes fly,' what you learn is not restricted to the particular aeroplanes you see or to the present context, but will provide you generic knowledge about the kind of artefact these planes belong to that is generalizable to other members of the category and to variable contexts. Moreover, the transmission of such generic knowledge is not restricted to linguistic communication. If I show you by manual demonstration how to open a milk carton, what you will learn is how to open that kind of container (i.e. you acquire kindgeneralizable knowledge from a single manifestation). In such cases, the observer does not need to rely on statistical procedures to extract the relevant information
} 
to be generalized because this is selectively manifested to her by the communicative demonstration." (Csibra and Gergely 2009, p. 148)

This type of generic generalizable knowledge, associated with categorization, seems reasonable to view as conceptual knowledge-what. Gärdenfors and Högberg point out that 'communicating concepts' is an evolutionarily prior form of teaching to 'explaining relationships between concepts' (Gärdenfors and Högberg 2017, pp. 193-195). According to Gärdenfors and Högberg, 'communicating concepts' at its core involves pattern-recognition, linking it to categorization and conceptual knowledge-what. 'Explaining relationships between concepts,' on the other hand, involves teaching of facts and symbolic language making it more readily linked to propositional knowledge-that (Gärdenfors and Högberg 2017, pp. 193-195).

A well-established position in cognitive psychology is that of the dual process framework (see, e.g., Lizardo et al. 2016). Specifically the (defaultinterventionist) dual process theory has been prominent, which divides mental processing into one unconscious implicit and one conscious explicit reasoning system (see, e.g., Bago and De Neys 2017; Lizardo et al. 2016; Huberdeau et al. 2015; Sloman 1993, 2014; Evans and Stanovich 2013; Kahneman 2011; Rugg and Curran 2007):

- System 1 operates automatically and quickly, with little or no effort and no sense of voluntary control. (Kahneman 2011, p. 20)

- System 2 allocates attention to the effortful mental activities that demand it, including complex computations. The operations of System 2 are often associated with the subjective experience of agency, choice, and concentration. (Kahneman 2011, p. 21)

System 1 (or Type 1) can be described as intuitive and heuristic whereas System 2 (or Type 2) is deliberate and analytical, where the slow analytical process tries to inhibit the faster intuitive process.

There are a number of alternative theories arguing that cognition should be seen as consisting of a single process, as well as theories arguing for the possibility of parallel additional and/or more fine-grained systems (see, e.g., Bago and De Neys 2017; Rugg and Curran 2007). But I will follow Smith and DeCoster (2000, p. 110) who argue that 'numerous models of dualprocessing modes can be integrated and interpreted in terms of the properties of two underlying memory systems and that this integration will lead to new insights and new predictions in several substantive areas of psychology.' (see also, e.g., Goel et al. 2000; Goel and Dolan 2003): 


\begin{abstract}
"The architecture that supports the interaction between systems has been hinted at in the cognitive neuroscience literature. Anatomically, the brain includes multiple parallel frontal corticobasal ganglia loops [...]. The interactions among these loops can be interpreted as a set of gating mechanisms [...]. My proposal is that one such loop is the intuitive loop, though it is best characterized as jointly intuitive and affective. Deliberation, in contrast, involves a more anterior prefrontal corticobasal ganglia loop. One critical function of deliberation is to serve to gate or at least modulate the intuitive-affective loop." (Sloman 2014, p. 75)
\end{abstract}

'System 1 is generally described as a form of universal cognition shared between humans and animals [... and] System 2 is believed to have evolved much more recently and is thought by most theorists to be uniquely human.' (Evans 2003, p. 454; see also Evans and Stanovich 2013, p. 225):

"Although rudimentary forms of higher order control can be observed in mammals and other animals [...], the controlled processing in which they can engage is very limited by comparison with humans, who have unique facilities for language and meta-representation as well as greatly enlarged frontal lobes [...]. We are in agreement that the facility for Type 2 thinking became uniquely developed in human beings, effectively forming a new mind [...], which coexists with an older mind based on instincts and associative learning and gives humans the distinctive forms of cognition that define the species [...]." (Evans and Stanovich 2013, p. 236)

System 1 is thus arguably compatible with the aforementioned $R T B$-account from cognitive ethology, and the two evolutionarily earlier memory forms (and knowledge forms) from cognitive neuroscience since ' $[\mathrm{t}]$ he capabilities of System 1 include innate skills that we share with other animals.' (Kahneman 2011, p. 21):

"System 1 is old in evolutionary terms and shared with other animals: it comprises a set of autonomous subsystems that include both innate input modules and domain-specific knowledge acquired by a domain-general learning mechanism. System 2 is evolutionarily recent and distinctively human: it permits abstract reasoning and hypothetical thinking, but is constrained by working memory capacity and correlated with measures of general intelligence." (Evans 2003, p. 454)

In other words can System 1, on a cognitive psychological level of analysis, be mapped to procedural memory (procedural knowledge) and semantic memory (conceptual knowledge), on a cognitive neuroscientific level of analysis, and to $R T B$, on a cognitive ethological level of analysis. System 1 is thus most naturally linked to externalist justification - even though semantic memory (conceptual knowledge) can be seen as an 'in-between,' containing both externalist and internalist elements.

By adding episodic memory (propositional knowledge), on the neuroscientific level of analysis, System 2, on the cognitive psychological level of 
analysis, can be illuminated. System 2 is viewed as 'the conscious, reasoning self that has beliefs, makes choices, and decides what to think about and what to do' (Kahneman 2011, p. 21). Episodic memory, governs conscious and active reflection where we have cognitive access to our beliefs, on the neuroscientific level of analysis. It thus makes it possible to account for internalist justification and 'the subjective experience of agency, choice, and concentration' (Kahneman 2011, p. 21), on the cognitive psychological level of analysis, which is needed to fully explain human cognition. The three memory systems, on the neuroscientific level of analysis, can hence explain both System 1 and System 2 on the cognitive psychological level of analysis. In support of such integration for example Lizardo et al. (2016) explicitly connect 'know how' and non-declarative representation to System 1, whereas 'know that' and declarative representation is connected to System 2:

"[... M] emory is divided into two main types, most commonly referred to as "declarative" and "nondeclarative" memory. Declarative memory (Type II) consists of consciously accessible memories of facts, symbols, and events, while nondeclarative memory (Type I) consists of relatively less accessible procedural knowledge, habits, and dispositions. The two kinds of memory are sometimes distinguished as "knowing that" and "knowing-how" [...], or "explicit" and "implicit" memory [...]." (Lizardo et al. 2016, section 3.2)

The discussion points in the direction of compatibility and a plausible integration of the models on the presented three levels of analysis.

\section{Conceptual Spaces: Knowledge-What and Categorization}

The conceptual spaces framework has been presented and developed by Gärdenfors as a complementary alternative to the conventional symbolic and subconceptual forms of representation (Gärdenfors 1990, 2000, 2014). It postulates geometrical structures, where 'phenomenal' quality dimensions are grouped into domains. Observations of objects can then, in accordance with their properties, be positioned in a dimensional region. Properties can thereafter be compared in regard of their relation, where relative proximity represents degree of 'similarity.' To fruitfully analyze properties, categories, and their relations, Gärdenfors proposes two definitional criteria that provides spatial structure:

Criterion P: A natural property is a convex region of a domain in a conceptual space, and; 
Criterion $C$ : A natural concept [or category] is represented as a set of convex regions in a number of domains together with an assignment of salience weights to the domains and information about how the regions in different domains are correlated.

The convexity of criterion $P$ is thought to capture that if two objects, exemplifying a property, are located in a particular domain, then objects positioned between those objects will also exemplify that same property. Criterion $C$ highlights that natural concepts and categories are based on one or more domains - a distinction that is lost in the traditional language-focused approach. Conceptual spaces thus offer the ability to add and adjust dimensions in a domain, making it possible to elucidate how they are similar and/or connected. Furthermore, conceptual spaces make it possible to clarify and explain category-formation and learning. So, by utilizing conceptual spaces and criteria $P$ and $C$ it is thus possible to model categorizations and the knowledge linked to them; i.e. conceptual knowledge-what (see, e.g., Gärdenfors 2000, 2014; see also Douven et al. 2013; Decock et al. 2013).

Focusing on knowledge-what and categorization, Gärdenfors and Williams (2001) specifically address how categorizations efficiently can be modeled with conceptual spaces. Even though their focus is on artificial intelligence, the framework has the ability to clearly show prototypes, independent dimensions, and similarity. They point out that " $\mathrm{t}$ ] here is a wealth of psychological data supporting the existence of prototypes and their key role in categorization' (Gärdenfors and Williams 2001, p. 387):

"In summary the key findings from psychological studies of categorization are (i) similarity judgments play a fundamental role in categorization and they are context sensitive, (ii) the degree of similarity is judged with respect to a reference object/region such as a prototype, (iii) category membership can be graded (discrete membership, if and when it exists, is considered to be a special case), and (iv) the psychophysical relationship between the stimulus and the response depends on the underlying categorization." (Gärdenfors and Williams 2001, p. 387)

I regard it to ultimately be up to any theoretician to investigate those domains and quality dimensions that are found to be of interest. But reconnecting to the above discussion about our evolutionarily molded cognitive faculties; there are some innate, natural, domains and quality dimensions for humans, and "[o] ur quality dimensions are what they are because they have been selected to fit the surrounding world.' (Gärdenfors 2000, p. 82) $\stackrel{4}{4}^{4}$

4 More or less similar domains and quality dimensions can also be found for other animals (see, e.g., Lorenz 1973; for an illuminating classic discussion see also Nagel 1974). 
Taken together, this strongly indicates that conceptual spaces are apt for investigating categorization and conceptual knowledge-what - the knowledge of what a category characteristically consists in.

\section{Concluding Remarks}

An integration of the neuroscientifically grounded knowledge-account with accounts from cognitive ethology and cognitive psychology has been shown to be plausible. Procedural and semantic memory, on a neuroscientific level of analysis, match an ethological reliabilist account, as well as System 1 from the psychological dual process theory. By adding episodic memory, on the neuroscientific level of analysis, System 2 on the psychological level can be accounted for. The article's integrative view is illustrated in Figure 2:

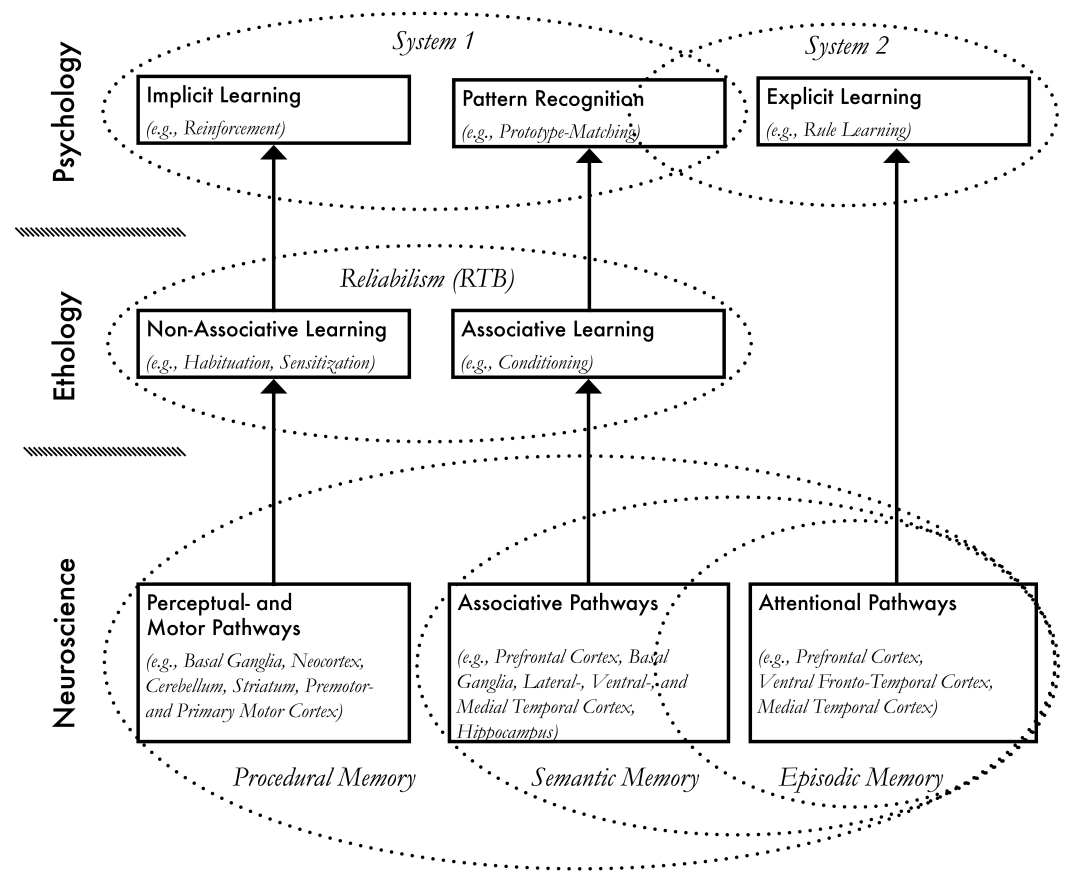

Figure 2 Knowledge seen from a neuroscientific, ethological, and psychological level of analysis. Dotted lines indicate knowledge-categories; boxes outline examples of more detailed content descriptions, and; arrows show hierarchical mappings.

This three-level naturalistic epistemological framework, linking conceptual knowledge-what to categorizations - fruitfully modeled within a conceptual spaces framework - promises interesting ramifications. On one hand it might 
fill a deleterious role and exert a dissolving influence on traditional epistemological problems and paradoxes. This is so since it moves a lot of focus away from propositional knowledge-that, which for a long time has had the center stage in epistemology, to conceptual knowledge-what. Moreover, it should impact discussions regarding, for example, reductionism since all three memory forms are considered important in their own right, which might be viewed as an argument against reduction. Importantly, if there is a reduction to be made it should be from propositional knowledge-that to conceptual knowledge-what and/or procedural knowledge-how, or from conceptual knowledge-what to procedural knowledge-how - not the other way around. On the other hand this nested take on naturalistic epistemology also offers a way to discover more and new scientifically grounded details regarding knowledge on other levels of analysis.

\section{Acknowledgements}

I have had the great pleasure and privilege of investigating and discussing these topics with Peter Gärdenfors, and I am very grateful to Peter for sharing his vast knowledge, his eye for detail, and his positive energy. I would also like to thank Mauri Kaipainen for his generous and insightful remarks. Thanks to Trond Arild Tjøstheim for inspiring discussions. Finally I would like to thank my anonymous reviewers for comments.

\section{References}

Allen, C., and Bekoff, M. (1995). Cognitive ethology and the intentionality of animal behaviour. Mind and Language, 10(4), 313-328.

Allen, T. A., and Fortin, N. J. (2013). The evolution of episodic memory. Proceedings of the National Academy of Sciences of the United States of America, 110(Supplement 2), 10379-10386.

Alston, W. P. (2005). Beyond "justification": Dimensions of epistemic evaluation. Ithaca: Cornell University Press.

Anderson, D. J., and Perona, P. (2014). Toward a science of computational ethology. Neuron, 84 (1), 18-31.

Avital, E., and Jablonka, E. (2000). Animal traditions: Behavioural inheritance in evolution. Cambridge: Cambridge University Press.

Bago, B., and De Neys, W. (2017). Fast logic?: Examining the time course assumption of dual process theory. Cognition, 158, 90-109. 
Barrett, H. C. (2015). The shape of thought: How mental adaptations evolve. Oxford: Oxford University Press.

Bermúdez, J. L. (2006). Knowledge, naturalism, and cognitive ethology: Kornblith's Knowledge and its place in nature. Philosophical Studies, 127(2), 299-316.

Berntson, G. G., and Cacioppo, J. T. (2009). Preface. In G. G. Berntson and J. T. Cacioppo (eds.), Handbook of neuroscience for the behavioral science (xi-xii). New York: John Wiley and Sons, Inc.

Binder, J. R., and Desai, R. H. (2011). The neurobiology of semantic memory. Trends in Cognitive Sciences, 15(11), 527-536.

Cellucci, C. (2017). Rethinking knowledge: The heuristic view. European Studies in Philosophy of Science (Vol. 4), Springer.

Clayton, N. S., Griffiths, D. P., Emery, N. J., and Dickinson, A. (2001). Elements of episodic - like memory in animals. Philosophical Transactions of the Royal Society B: Biological Sciences, 356(1413), 1483-1491.

Csibra, G., and Gergely, G. (2006). Social learning and social cognition: the case for pedagogy. In Y. Munakata and M.H. Johnson (eds.), Processes of change in brain and cognitive development. Attention and performance XXI (249-274). Oxford: Oxford University Press.

Csibra, G., and Gergely, G. (2009). Natural pedagogy. Trends in Cognitive Sciences, 13(4), 148-153.

Decock, L., Dietz, R., and Douven, I. (2013). Modelling comparative concepts in conceptual spaces. In Y. Motomura, A. Butler and D. Bekki (eds.), New Frontiers in Artificial Intelligence (69-86). Heidelberg: Springer.

Douven, I., Decock, L., Dietz, R., and gr, P. (2013). Vagueness: A conceptual spaces approach. Journal of Philosophical Logic, 42(1), 137-160.

Dupré, J. (1993). The disorder of things: Metaphysical foundations of the disunity of science. Cambridge, MA: Harvard University Press.

Evans, J. S. B. (2003). In two minds: Dual-process accounts of reasoning. Trends in Cognitive Sciences, 7(10), 454-459.

Evans, J. S. B., and Stanovich, K. E. (2013). Dual-process theories of higher cognition: Advancing the debate. Perspectives on Psychological Science, $8(3), 223-241$.

Fantl, J. (2016). Knowledge how. In E. N. Zalta (ed.), The Stanford Encyclopedia of Philosophy (Spring 2016 Edition). https://plato.stanford.edu/archives/spr2016/entries/knowledge-how/

Fletcher, P. C., Büchel, C., Josephs, O., Friston, K., and Dolan, R. J. (1999). Learning-related neuronal responses in prefrontal cortex studied with functional neuroimaging. Cerebral Cortex, 9(2), 168-178.

Frank, M. J., and Badre, D. (2015). How cognitive theory guides neuroscience. Cognition, 135, 14-20 
Gärdenfors, P. (1990). Induction, conceptual spaces and AI. Philosophy of Science, 57(1), 78-95.

Gärdenfors, P. (2000). Conceptual spaces: The geometry of thought. Cambridge, MA: Bradford Books, MIT Press.

Gärdenfors, P. (2014). The geometry of meaning: Semantics based on conceptual spaces. Cambridge, MA: MIT Press.

Gärdenfors, P., and Högberg, A. (2017). The archaeology of teaching and the evolution of Homo docens. Current Anthropology, 58(2), 188-208.

Gärdenfors, P., and Stephens, A. (2017). Induction and knowledge-what. European Journal for Philosophy of Science, 1-21. DOI: 10.1007/s13194017-0196-y.

Gärdenfors, P., and Williams, M. A. (2001). Reasoning about categories in conceptual spaces. In Proceedings of the Fourteenth International Joint Conference of Artificial Intelligence (385-392). Morgan Kaufmann Publishers.

Gergely, G., Egyed, K., and Kirly, I. (2007). On pedagogy. Developmental Science, 10(1), 139-146.

Goel, V., Buchel, C., Frith, C., and Dolan, R. J. (2000). Dissociation of mechanisms underlying syllogistic reasoning. Neuroimage, 12(5), 504514.

Goel, V., and Dolan, R. J. (2000). Anatomical segregation of component processes in an inductive interference task. Journal of Cognitive Neuroscience, 12(1), 110-119.

Goel, V., and Dolan, R. J. (2003). Explaining modulation of reasoning by belief. Cognition, 87(1), B11-B22.

Goldman, A., and Beddor, B. (2016). Reliabilist epistemology. In E. N. Zalta (ed.), The Stanford Encyclopedia of Philosophy (Winter 2016 Edition). https://plato.stanford.edu/archives/win2016/entries/reliabilism/

Grossman, M., Koenig, P., DeVita, C., Glosser, G., Alsop, D., Detre, J., and Gee, J. (2002). The neural basis for category-specific knowledge: An fMRI study. Neuroimage, 15(4), 936-948.

Grossman, M., Smith, E. E., Koenig, P., Glosser, G., DeVita, C., Moore, P., and McMillan, C. (2002). The neural basis for categorization in semantic memory. Neuroimage, 17(3), 1549-1561.

Horst, S. (2016). Cognitive pluralism. Cambridge, MA: The MIT Press.

Huberdeau, D. M., Krakauer, J. W., and Haith, A. M. (2015). Dual-process decomposition in human sensorimotor adaptation. Current Opinion in Neurobiology, 33, 71-77.

Irish, M., and Piguet, O. (2013). The pivotal role of semantic memory in remembering the past and imagining the future. Frontiers in Behavioral Neuroscience, 7(27), 1-11. 
Kahneman, D. (2011). Thinking fast and slow. New York: Farrar, Straus and Giroux.

Kan, I. P., Alexander, M. P., and Verfaellie, M. (2009). Contribution of prior semantic knowledge to new episodic learning in amnesia. Journal of Cognitive Neuroscience, 21 (5), 938-944.

Kandel, E. R., Schwartz, J. H., Jessell, T. M., Siegelbaum, S. A., and Hudspeth, A. J. (eds.). (2013). Principles of neural science (5th Edition). New York: McGraw-Hill, Health Professions Division.

Kim, H. (2016). Default network activation during episodic and semantic memory retrieval: A selective meta-analytic comparison. Neuropsychologia, 80, 35-46.

Kornblith, H. (1993). Inductive inference and its natural ground: An essay in naturalistic epistemology. Cambridge, MA: MIT Press.

Kornblith, H. (2002). Knowledge and its place in nature. Oxford: Oxford University Press.

Krakauer, J. W., Ghazanfar, A. A., Gomez-Marin, A., MacIver, M. A., and Poeppel, D. (2017). Neuroscience needs behavior: Correcting a reductionist bias. Neuron, 93(3), 480-490.

Kusch, M. (2005). Beliefs, kinds and rules: A comment on Kornblith's Knowledge and its place in nature. Philosophy and Phenomenological Research, 71(2), 411-419.

Lizardo, O., Mowry, R., Sepulvado, B., Stoltz, D. S., Taylor, M. A., Van Ness, J., and Wood, M. (2016). What are dual process models? Implications for cultural analysis in sociology. Sociological Theory, 34(4), 287-310.

Lorenz, K. (1973/1977). Behind the mirror: A search for a natural history of human knowledge. London: Methuen.

Markie, P. (2013). Rationalism vs. empiricism. In E. N. Zalta (ed.), The Stanford Encyclopedia of Philosophy (Summer 2013 Edition). http://plato.stanford.edu/archives/sum2013/entries/rationalism-empiricism/

Mitchell, S. D. (2003). Biological complexity and integrative pluralism. Cambridge: Cambridge University Press.

Nagel, T. (1974). What is it like to be a bat?. The Philosophical Review, $83(4), 435-450$.

Panoz-Brown, D., Corbin, H. E., Dalecki, S. J., Gentry, M., Brotheridge, S., Sluka, C. M., Wu, J., and Crystal, J. D. (2016). Rats remember items in context using episodic memory. Current Biology, 26(20), 2821-2826.

Pappas, G. (2017). Internalist vs. externalist conceptions of epistemic justification. In E. N. Zalta (ed.), The Stanford Encyclopedia of Philosophy (Fall 2017 Edition).

https://plato.stanford.edu/archives/fall2017/entries/justep-intext/ 
Plotkin, H. C. (1993). Darwin machines and the nature of knowledge. Cambridge, MA: Harvard University Press.

Renoult, L., Tanguay, A., Beaudry, M., Tavakoli, P., Rabipour, S., Campbell, K., Moscovitch, M., Levine, B., and Davidson, P. S. (2016). Personal semantics: Is it distinct from episodic and semantic memory? An electrophysiological study of memory for autobiographical facts and repeated events in honor of Shlomo Bentin. Neuropsychologia, 83, 242-256.

Rilling, J. K., Barks, S. K., Parr, L. A., Preuss, T. M., Faber, T. L., Pagnoni, G., Bremer, D., and Votaw, J. R. (2007). A comparison of resting-state brain activity in humans and chimpanzees. Proceedings of the National Academy of Sciences of the United States of America, 104(43), 1714617151.

Roberts, W. A. (2016). Episodic memory: Rats master multiple memories. Current Biology, 26(20), R920-R922.

Rosch, E. (1975a). Cognitive reference points. Cognitive Psychology, 7(4), 532-547.

Rosch, E. (1975b). Cognitive representations of semantic categories. Journal of experimental psychology: General, 104(3), 192-233.

Rugg, M. D., and Curran, T. (2007). Event-related potentials and recognition memory. Trends in Cognitive Sciences, 11(6), 251-257.

Ryle, G. (1949). The concept of mind. London: Hutchinson.

Samet, J., and Zaitchik, D. (2014). Innateness and contemporary theories of cognition. In E. N. Zalta (ed.), The Stanford Encyclopedia of Philosophy (Fall 2014 Edition).

http://plato.stanford.edu/archives/fall2014/entries/innateness-cognition/

Serrelli, E., and Rossi, F. M. (2009). A conceptual taxonomy of adaptation in evolutionary biology. Draft paper 4 sept., Milano: University of Milano Bicocca.

Shettleworth, S. J. (2010). Cognition, evolution, and behavior. Oxford University Press.

Sloman, S. A. (1993). Feature-based induction. Cognitive Psychology, 25(2), 231-280.

Sloman, S. A. (2014). Two systems of reasoning: An update. In J. W. Sherman, B. Gawronski, and Y. Trope (eds.), Dual-process theories of the social mind (69-79). New York: Guilford Press.

Smith, E. R., and DeCoster, J. (2000). Dual-process models in social and cognitive psychology: Conceptual integration and links to underlying memory systems. Personality and Social Psychology Review, 4(2), 108-131.

Stanley, J. (2011). Know how. Oxford: Oxford University Press.

Tulving, E. (1972). Episodic and semantic memory. In E. Tulving and W. Donaldson (eds.), Organization of memory (381-403). New York: 
Academic Press.

Tulving, E. (1985). Memory and consciousness. Canadian Psychology, 26(1), $1-12$.

Tulving, E. (2002). Episodic memory: From mind to brain. Annual Review of Psychology, 53(1), 1-25.

Tulving, E. (2005). Episodic memory and autonoesis: Uniquely human. In H. Terrance and J. Metcalfe (eds.), The missing link in cognition: Origins of self-reflective consciousness (3-56). New York: Oxford University Press.

Ullman, M. T. (2016). The declarative/procedural model: A neurobiological model of language learning, knowledge and use. In G. Hickok and S. L. Small (eds.), The neurobiology of language (953-968). London: Academic Press.

Wynne, C. D. L. (2007). What are animals? Why anthropomorphism is still not a scientific approach to behavior. Comparative Cognition and Behavior Reviews, 2: 125?135.

Yee, E., Chrysikou, E. G., and Thompson-Schill, S. L. (2014). Semantic memory. In K. Ochsner and S. Kosslyn (eds.), The Oxford Handbook of Cognitive Neuroscience: Volume 1, Core Topics (353-374). Oxford: Oxford University Press. 